\title{
Prenatal care among mothers involved with child protection services in Manitoba: a retrospective cohort study
}

\author{
Elizabeth Wall-Wieler PhD, Kathleen Kenny MHSc, Janelle Lee BSc, Kellie Thiessen RM RN PhD, \\ Margaret Morris MD MEd, Leslie L. Roos PhD
}

Cite as: CMAJ 2019 February 25;191:E209-15. doi: 10.1503/cmaj.181002

See related article at www.cmaj.ca/lookup/doi/10.1503/cmaj.190183

Visual abstract available at www.cmaj.ca/lookup/suppl/doi:10.1503/cmaj.181002/-/DC2

\section{ABSTRACT}

BACKGROUND: Prenatal care is one of the most widely used preventive health services; however, use varies substantially. Our objective was to examine prenatal care among women with a history of having a child placed in out-of-home care, and whether their care differed from care among women who did not.

METHODS: We used linkable administrative data to create a population-based cohort of women whose first 2 children were born in Manitoba, Canada, between Apr. 1, 1998, and Mar. 1, 2015. We measured the level of prenatal care using the Revised Graduated Prenatal Care Utilization Index, which categorizes care into 5 groups: intensive, adequate, intermediate, inadequate and no care. We compared level of prenatal care for women whose first child was placed in care with level of prenatal care for women who had no contact with care services, using 2 multinomial logistic regression models to calculate odds ratios (ORs).

RESULTS: In a cohort of 52438 mothers, $1284(2.4 \%)$ had their first child placed in out-of-home care before conception of their second child. Mothers whose first child was placed in care had much higher rates of inadequate prenatal care during the pregnancy with their second child than mothers whose first child was not placed in care (33.0\% v. $13.4 \%)$. The odds of having inadequate rather than adequate prenatal care were more than 4 times higher (OR $4.29,95 \% \mathrm{Cl} 3.68$ to 5.01) for women who had their first child placed in care than for women who did not have their first child placed in care.

INTERPRETATION: Mothers with a history of having a child taken into care by the child protection services system are at higher risk of having inadequate or no prenatal care in a subsequent pregnancy compared with mothers with no history of involvement with child protection services.

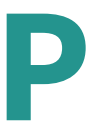

renatal care is one of the most widely used preventive health services in North America. Women receiving prenatal care are more likely to have risk factors associated with poor birth outcomes identified and addressed..$^{1,2}$ Although adequate prenatal care benefits maternal and child health outcomes during pregnancy and after birth, not all pregnant women access such care, with use varying based on individual and social factors. $^{3-5}$ Individual-level factors associated with inadequate prenatal care include mother's age, marital status and attitudes around pregnancy; neighbourhood income and residence in an urban or rural area also play a role in the likelihood of receiving adequate prenatal care. ${ }^{5-8}$ Inadequate prenatal care has been associated with increased involvement with child protection services. Analysis of data from a 2002 birth cohort of children born in California whose mothers received no prenatal care showed that almost half of the children were placed in out-of-home care; of those placed in care, nearly two-thirds were placed within the first 3 days of life. ${ }^{9} \mathrm{~A}$ Can- adian population-based analysis also showed that inadequate prenatal care is a strong predictor of having children placed in out-ofhome care at birth. ${ }^{10}$

Although women whose children are placed in care are more likely to have a history of low prenatal care use, it is not known whether involvement with child protection services is related to level of use of prenatal care in subsequent pregnancies. Understanding this relation is particularly important in Canada, as the rates of children in out-of-home care are high, with more than $3 \%$ of children in care in Manitoba, compared with less than $1 \%$ of children in most developed countries. ${ }^{11}$ Furthermore, in Manitoba, 22.5\% of mothers do not receive adequate care; this is higher than the Canadian rate of $18.9 \%$ and lower than the American rate of $29.5 \% .3 .12$

Our objective was to compare the level of use of prenatal care during a second pregnancy among Manitoba women whose first child was placed in out-of-home care and those whose first child was not placed in care. 


\section{Methods}

\section{Study population and data sources}

Manitoba is a central Canadian province with 1.3 million residents and about 16000 births each year. ${ }^{13}$ Through the universal health care insurance plan, all women in Manitoba who become pregnant are eligible to receive prenatal care without payment.

We used data housed at the Manitoba Centre for Health Policy within the Department of Community Health Sciences, in the Max Rady College of Medicine, Rady Faculty of Health Sciences at the University of Manitoba, Winnipeg, to create a population-based cohort of women whose first 2 children were born in Manitoba between Apr. 1, 1998, and Mar. 1, 2015. We used an anonymized personal health number to link the population registry, physician claims, child protection case files, admissions to hospital, employment and income assistance (analogous to welfare) case files, and the BabyFirst and Families First Screening files; these data sets were all de-identified. ${ }^{14}$ The BabyFirst or Families First Screen form is completed by a public health nurse after the birth of a child and captures biological, social and demographic information for the child and their family; these forms were completed for most newborns starting in 2000. We obtained neighbourhood information from Canadian Census data, with the 6-digit postal code from the population registry linked to a census dissemination area. ${ }^{15}$ Information on linkage methods, confidentiality, privacy and validity is fully documented; linkage errors occur in less than $1 \%$ of cases. ${ }^{16-18}$

\section{Variables}

\section{Level of prenatal care utilization}

Information on prenatal care utilization was obtained through physician claims and calculated using the Revised Graduated Prenatal Care Utilization Index (R-GINDEX), which adheres to the American College of Obstetricians and Gynecology guidelines on the adequate number of prenatal care visits, accounting for the trimester in which prenatal care started and the gestational age of the child. ${ }^{19}$ We excluded all mothers with missing information on prenatal care utilization: the following 5 major prenatal care categories of the R-GINDEX remained: intensive, which is indicative of a high-risk pregnancy, adequate, intermediate, which corresponds to having about $50 \%-80 \%$ of recommended visits, inadequate, which corresponds to having less than $50 \%$ of recommended visits, and no care. ${ }^{20}$

\section{Out-of-home care}

Information on out-of-home care was obtained from the Child and Family Services Information System provided through Child and Family Services in Manitoba. ${ }^{21}$ Our primary outcome was whether a mother's first child was taken into out-of-home care before conception of her second child. We divided timing of placement into 2 groups at birth, defined as a case being opened during the mother's hospital stay for delivery, and after birth, defined as any time between the admission to hospital for delivery and conception of the second child. Mothers were defined as being reunified with their first child if the case was closed before the conception of the second child.

\section{Covariates}

To account for potential confounders, covariates during 3 time periods were included: during the pregnancy of the first child, at the birth of the first child, and between the birth of the first child and the pregnancy of the second child. During the pregnancy of the first child, we considered a maternal diagnosis of substance use disorder and her level of prenatal care.22 Substance use disorder was defined as at least 1 physician visit or at least 1 admission with a diagnosis of substance use disorder (clinical modification of the International Classification of Diseases, 9th revision [ICD-9-CM] codes 291, 293, 303-305; enhanced Canadian version of the International Statistical Classification of Diseases and Related Health Problems, 10th Revision [ICD-10-CA] codes F10F19, F55), and prenatal care was defined as above. ${ }^{23}$

At the birth of the first child, we considered the year (19982003, 2004-2009, 2010-2015) to account for potential changes in policies, mother's age, location (urban was defined as neighbourhoods in Winnipeg and Brandon, and rural was defined as all other Manitoba neighbourhoods) and income quintile of the neighbourhood in which the mother lived. 5,24,25 Information for 3 social variables at the birth of the first child were available for a subpopulation of women for whom the BabyFirst or Families First Screen form was completed: education (less than high school/completed high school), single mother (yes/no) and social isolation (yes/no). ${ }^{24}$

In the interval between the birth of the mother's first child and conception of her second child, we considered the length of this time period, whether she had moved (defined as at least 1 change in postal code), received income assistance (for at least 2 consecutive months), or had been diagnosed with substance use disorder, diabetes or hypertension. ${ }^{24,26}$ We defined diabetes as at least 1 physician visit or at least 1 admission to hospital with a diagnosis of diabetes (ICD-9-CM code 250; ICD-10-CA codes E10-E14), and hypertension as at least 1 physician visit or at least 1 admission to hospital with a diagnosis of hypertension (ICD-9-CM codes 401-405; ICD-10-CA codes I10-I13, I15). ${ }^{24}$

\section{Statistical analysis}

We first compared characteristics of mothers having their first child placed in out-of-home care with those who did not using standardized differences; we denoted standardized differences greater than 0.1 or less than -0.1 as having meaningful imbalance between the 2 groups of women. ${ }^{27}$ Next, we obtained unadjusted and adjusted odds ratios (ORs) for level of prenatal care for these 2 groups of mothers using multinomial logistic regression models, with mothers receiving adequate care as the reference group. We examined 2 adjusted models - the first included all covariates before and at the birth of the first child, and the second incorporated these variables, as well as the covariates between the births of the first and second child. This approach was used as events between the birth of the first and conception of the second child may have occurred after the child was placed in out-of-home care, placing them on the causal pathway.

Prenatal care utilization during the pregnancy of the second child could be affected by the timing of the first child's placement or by a mother's reunification with her first child. Timing 
and reunification may be important when examining this association; placement in out-of-home care during the mother's admission to hospital for delivery could indicate that a birth alert was issued for the mother during her first pregnancy. Mothers who are not reunited with their first child may be considered at higher risk of having a birth alert issued. To study these differences further, we conducted sensitivity analyses, excluding women who did not have a child placed in care. Among women whose first child was placed in care, we examined whether the level of prenatal care utilization for the second child differed if the first child was placed in out-of-home care at birth or after birth, and whether the level of prenatal care utilization for the second child differed if the mother was reunified with her first child before conceiving her second child. Again, we used multinomial logistic regression models to obtain unadjusted and adjusted ORs. These adjusted models included covariates before and at the birth of the first child. For all analyses, we considered a $p$ value less than 0.05 to be significant. Data management, programming and analyses were performed using SAS version 9.4.

\section{Ethics approval}

This study was approved by the Health Research Ethics Board at the University of Manitoba (no. H2016:182) and the Health Information Privacy Commission at Manitoba Health, Seniors and Active Living (no. 2016/2017-09). Because we used de-identified administrative data files, we did not require informed consent from participants.

\section{Results}

The cohort consisted of all 52607 mothers with at least 2 children whose oldest 2 children were born in Manitoba between Apr. 1, 1998, and Mar. 31, 2015, and lived in Manitoba from the conception of their first child to the birth of their second child; 169 mothers $(0.3 \%)$ were excluded because of missing information on prenatal care during at least 1 pregnancy. Our final cohort included 52438 mothers, of which 1284 (2.4\%) had their first child placed in out-of-home care before conception of their second child. Mothers whose first child was placed in out-ofhome care had higher rates of substance use diagnoses, were more likely to live in urban and low-income neighbourhoods, more likely to have moved and received income assistance, and had higher rates of diabetes diagnoses (Table 1). Women whose first child was placed in care also had lower rates of adequate prenatal care during the pregnancy of their first child.

Women whose first child was placed in out-of-home care had more than twice the rate of inadequate care during the pregnancy of their second child than women whose first child was not placed (33.0\% v. 13.4\%) (Table 2). After adjusting for all covariates, the odds of having intermediate rather than adequate prenatal care were $28 \%$ greater ( $95 \% \mathrm{Cl} 9 \%$ to $50 \%$ ), whereas the odds of having inadequate rather than adequate prenatal care were $46 \%$ greater ( $95 \% \mathrm{Cl} 22 \%$ to $75 \%$ ) for women having their first child placed in care than for women not having their first child placed in care. A sensitivity analysis that adjusted for education, marital status and social support data available for a subpopulation found that inclusion of these variables did not change the results significantly (Appendix 1, Supplemental Table 1, Supplemental Table 2, available at www.cmaj.ca/ lookup/suppl/doi:10.1503/cmaj.181002/-/DC1).

Our adjusted models controlled for levels of prenatal care in the first pregnancy; however, simply comparing rates of inadequate or no prenatal care in the first 2 pregnancies indicated a decrease in level of prenatal care in the second pregnancy for both groups of women. Tables 1 and 2 show that, among women whose first child was not placed in care, the rate of having inadequate care went from $19.1 \%$ in their first pregnancy to $13.4 \%$ in their second. A smaller decrease was seen among women whose first child was placed in care; the rate of inadequate care decreased from $35.2 \%$ in the first pregnancy to $33.0 \%$ in the second pregnancy.

Of the 1284 mothers whose first child was placed in out-ofhome care before the conception of their second child, 395 (30.7\%) were separated from their first child at birth (Table 3); timing of separation did not affect rates of prenatal care during the pregnancy of their second child. Just over half of mothers who were separated from their first child $(n=690,53.7 \%)$ were reunified with their first child before the conception of their second child (Table 4); there was no relation between reunification status and level of prenatal care utilization during pregnancy of second child.

\section{Interpretation}

We were able to conduct a population-based analysis of the use of prenatal care among women who have a child placed in outof-home care because of the unique linkages between child welfare data and use of health services in Manitoba. Mothers whose first child was placed in out-of-home care had higher odds of receiving inadequate or no prenatal care in their next pregnancy than mothers whose children were not placed in out-of-home care. Among mothers whose first child was placed in out-ofhome care, the odds of inadequate prenatal care were not affected by the timing of the placement of the first child or by the mother's reunification status with her first child.

Previous research has identified a fear of detection or involvement with child protection services as an important barrier for at-risk pregnant women, potentially leading to disengagement from, avoidance of or delayed presentation to prenatal care..$^{28-30}$ We expect this fear to be intensified for pregnant women who had their first child taken into care by child protection services because they may fear this happening again. Innovation in outreach strategies to engage such women, including flexible service delivery models that work with women where they are e.g., on the streets, in their homes, in shelters, in remote communities - to reduce barriers such as lack of transportation and distrust of formal settings in health care may help to improve engagement. ${ }^{31}$

Pregnancy presents an important opportunity to increase positive outcomes for vulnerable women and to enable children to have the best possible start in life. This represents an obligation within the child rights principles and a crucial strategy for reducing population-level health disparities. ${ }^{32,33}$ To ensure better use of prenatal care, provincial practices concerning notifications 
to child protection case workers by prenatal care providers upon determination that a woman is at risk of not being able to care for her child, which generally triggers a birth alert, may need to be re-evaluated. Strategies for harm reduction may be considered to support women in challenging circumstances to improve their health during pregnancy and engage with prenatal care. Positive outcomes in attendance at prenatal care for women who use drugs have been shown in "one-stop" harm reductionbased programs, such as the Healthy, Empowered and Resilient (H.E.R.) Pregnancy Program in Edmonton and Manito Ikwe
Kagiikwe in Winnipeg. These programs offer marginalized pregnant women, many of whom are Indigenous, a holistic approach to services centred around "best practices" of engagement and outreach, harm reduction, cultural safety, and support of mother and child, as well as a strong emphasis on practical support (e.g., prenatal vitamins, food vouchers, socks, bus tickets and housing support). ${ }^{31,34}$ Ultimately, models for harm reduction provide a nonjudgmental low-barrier approach to building relationships with pregnant women that could address such adverse circumstances as poverty, violence and lack of access to prenatal care. ${ }^{35}$

Table 1: Characteristics of the study population

\begin{tabular}{|c|c|c|c|}
\hline \multirow[b]{2}{*}{ Characteristic } & \multicolumn{2}{|c|}{$\begin{array}{c}\text { No. }(\%)^{\star} \text { of mothers } \\
n=52438\end{array}$} & \multirow[b]{2}{*}{$\begin{array}{c}\text { Standardized differences } \\
\qquad(95 \% \mathrm{Cl})\end{array}$} \\
\hline & $\begin{array}{l}\text { First child taken into care } \\
\text { before conception of } \\
\text { second child } \\
n=1284\end{array}$ & $\begin{array}{l}\text { First child not taken into } \\
\text { care before birth of } \\
\text { second child } \\
n=51154\end{array}$ & \\
\hline \multicolumn{4}{|l|}{ During pregnancy of first child } \\
\hline Diagnosis of substance use disorder & $119(9.3)$ & $588(1.2)$ & $0.37(0.31$ to 0.42$)$ \\
\hline \multicolumn{4}{|l|}{ Prenatal care (R-GINDEX) } \\
\hline Intensive & $60(4.7)$ & $2359(4.6)$ & 0 (-0.05 to 0.06$)$ \\
\hline Adequate & $250(19.5)$ & $19507(38.1)$ & $-0.42(-0.48$ to -0.36$)$ \\
\hline Intermediate & $455(35.4)$ & $17960(35.1)$ & $0.01(-0.05$ to 0.06$)$ \\
\hline Inadequate & $452(35.2)$ & $9749(19.1)$ & 0.37 (0.31 to 0.42$)$ \\
\hline No care & $67(5.2)$ & $1579(3.09)$ & $0.11(0.05$ to 0.16$)$ \\
\hline \multicolumn{4}{|l|}{ At birth of first child } \\
\hline \multicolumn{4}{|l|}{ Year } \\
\hline 1998-2003 & $461(35.9)$ & $17316(33.9)$ & $0.04(-0.01$ to 0.1$)$ \\
\hline 2004-2009 & $550(42.8)$ & $21533(42.1)$ & $0.01(-0.04$ to 0.07$)$ \\
\hline 2010-2015 & $273(21.3)$ & $12305(24.1)$ & $-0.07(-0.12$ to -0.01$)$ \\
\hline Mother's age, mean \pm SD; yr & $19.1 \pm 3.5$ & $25.7 \pm 5.4$ & $-0.09(-0.15$ to -0.04$)$ \\
\hline Urban neighbourhood & $828(64.5)$ & $29828(58.3)$ & $0.13(0.07$ to 0.18$)$ \\
\hline \multicolumn{4}{|l|}{ Income quintile of neighbourhood } \\
\hline 1 (Lowest income) & $714(55.6)$ & $11864(23.2)$ & 0.7 (0.65 to 0.76$)$ \\
\hline 2 & $246(19.2)$ & $10894(21.3)$ & $-0.05(-0.11$ to 0.00$)$ \\
\hline 3 & $147(11.5)$ & $10069(19.7)$ & $-0.23(-0.28$ to -0.17$)$ \\
\hline 4 & $77(6.0)$ & $9867(19.3)$ & $-0.41(-0.46$ to -0.35$)$ \\
\hline 5 (Highest income) & $62(4.8)$ & $8317(16.3)$ & $-0.38(-0.44$ to -0.33$)$ \\
\hline Missing data & $38(3.0)$ & $143(0.3)$ & 0.21 (0.16 to 0.27$)$ \\
\hline \multicolumn{4}{|c|}{ Between birth of first child and conception of second child } \\
\hline Time period, mean $\pm \mathrm{SD}$; $\mathrm{yr}$ & $2.9 \pm 2.4$ & $2.2 \pm 1.8$ & $0.04(-0.01$ to 0.10$)$ \\
\hline Moved & $827(64.4)$ & $18386(35.9)$ & 0.59 (0.54 to 0.65$)$ \\
\hline Received income assistance & $883(68.8)$ & $6879(13.5)$ & 1.36 (1.30 to 1.41$)$ \\
\hline Diagnosis of diabetes & $50(3.9)$ & $831(1.6)$ & 0.14 (0.09 to 0.20$)$ \\
\hline Diagnosis of hypertension & $41(3.2)$ & $1890(3.7)$ & $-0.03(-0.08$ to 0.03$)$ \\
\hline Diaganosis of substance use disorder & 320 (24.9) & $1425(2.8)$ & $0.68(0.62$ to 0.73$)$ \\
\hline
\end{tabular}




\begin{tabular}{|c|c|c|c|c|c|}
\hline \multirow[b]{2}{*}{$\begin{array}{l}\text { Level of prenatal } \\
\text { care utilization }\end{array}$} & \multicolumn{2}{|c|}{$\begin{array}{c}\text { No. }(\%) \text { of mothers } \\
n=52438\end{array}$} & \multirow{2}{*}{$\begin{array}{c}\text { Model } 1 \\
\text { Unadjusted OR } \\
\text { (95\% CI) }\end{array}$} & \multirow{2}{*}{$\begin{array}{c}\text { Model } 2 \\
\text { Adjusted OR* } \\
(95 \% \mathrm{CI})\end{array}$} & \multirow{2}{*}{$\begin{array}{c}\text { Model } 3 \\
\text { Adjusted OR† } \\
(95 \% \mathrm{CI})\end{array}$} \\
\hline & $\begin{array}{l}\text { First child placed in care } \\
\text { before conception of } \\
\text { second child } \\
\text { ( } n=1284)\end{array}$ & $\begin{array}{l}\text { First child not placed in } \\
\text { care before birth of } \\
\text { second child } \\
\text { ( } n=51154)\end{array}$ & & & \\
\hline Intensive & $50(3.9)$ & $1679(3.3)$ & 2.07 (1.52 to 2.81 ) & 1.52 (1.11 to 2.10$)$ & 1.32 (0.95 to 1.84$)$ \\
\hline Adequate & $273(21.3)$ & $18948(37.0)$ & 1.00 (Ref.) & 1.00 (Ref.) & 1.00 (Ref.) \\
\hline Intermediate & $493(38.4)$ & $22009(43.0)$ & $1.55(1.34$ to 1.80$)$ & 1.30 (1.11 to 1.52$)$ & 1.28 (1.09 to 1.50$)$ \\
\hline Inadequate & $424(33.0)$ & $6855(13.4)$ & 4.29 (3.68 to 5.01$)$ & 1.44 (1.21 to 1.71$)$ & $1.46(1.22$ to 1.75$)$ \\
\hline No care & $44(3.4)$ & $1663(3.3)$ & 1.84 (1.33 to 2.53$)$ & 0.84 (0.59 to 1.18$)$ & 0.99 (0.70 to 1.42$)$ \\
\hline
\end{tabular}

Table 3: Adjusted and unadjusted odds ratios for inadequate prenatal care during pregnancy of second child among mothers whose first child was taken into care before conception of second child, by timing of first child's placement in care

\begin{tabular}{|c|c|c|c|c|}
\hline \multirow[b]{2}{*}{ Level of prenatal care } & \multicolumn{2}{|c|}{$\begin{array}{c}\text { No. }(\%) \text { of mothers } \\
n=1284\end{array}$} & \multirow[b]{2}{*}{ Unadjusted OR (95\% CI) } & \multirow[b]{2}{*}{ Adjusted* OR $(95 \% \mathrm{CI})$} \\
\hline & $\begin{array}{l}\text { First child was placed in } \\
\begin{array}{l}\text { care at birth } \\
n=395\end{array}\end{array}$ & $\begin{array}{l}\text { First child was placed in } \\
\text { care after birth } \\
n=889\end{array}$ & & \\
\hline Intensive & $15(3.8)$ & $35(3.9)$ & 0.92 (0.48 to 1.51 ) & 0.92 (0.48 to 1.77 ) \\
\hline Adequate & $87(22.0)$ & $186(20.9)$ & 1.00 (Ref.) & 1.00 (Ref.) \\
\hline Intermediate & $132(33.4)$ & $361(40.6)$ & 0.78 (0.57 to 1.08$)$ & 0.78 (0.57 to 1.08$)$ \\
\hline Inadequate & $143(36.2)$ & $281(31.6)$ & 1.09 (0.79 to 1.51$)$ & 1.09 (0.79 to 1.51$)$ \\
\hline No care & $18(4.6)$ & $26(2.9)$ & 1.48 (0.77 to 2.84$)$ & 1.48 (0.77 to 2.84$)$ \\
\hline
\end{tabular}

Table 4: Adjusted and unadjusted odds ratios for inadequate prenatal care during pregnancy of second child among mothers whose first child was taken into care before conception of second child, by reunification status with first child

\begin{tabular}{|c|c|c|c|c|}
\hline \multirow[b]{2}{*}{ Level of prenatal care } & \multicolumn{2}{|c|}{$\begin{array}{c}\text { No. }(\%) \text { of mothers } \\
n=1284\end{array}$} & \multirow[b]{2}{*}{ Unadjusted OR (95\% Cl) } & \multirow[b]{2}{*}{ Adjusted* OR $(95 \% \mathrm{Cl})$} \\
\hline & $\begin{array}{l}\text { Reunited with first child } \\
\text { before conception of } \\
\text { second child } \\
n=690\end{array}$ & $\begin{array}{l}\text { Not reunited with first } \\
\text { child before conception of } \\
\text { second child } \\
n=594\end{array}$ & & \\
\hline Intensive & $27(3.9)$ & $23(3.9)$ & 0.89 (0.49 to 1.64$)$ & $0.79(0.42$ to 1.48$)$ \\
\hline Adequate & $155(22.5)$ & $118(19.9)$ & 1.00 (Ref.) & 1.00 (Ref.) \\
\hline Intermediate & $268(38.8)$ & $225(37.9)$ & 0.91 (0.67 to 1.22$)$ & $0.88(0.65$ to 1.20$)$ \\
\hline Inadequate & $227(32.9)$ & $197(33.2)$ & 0.88 (0.65 to 1.19$)$ & 0.83 (0.60 to 0.15$)$ \\
\hline No care & $13(1.9)$ & $31(5.2)$ & 0.32 (0.16 to 0.64$)$ & 0.31 (0.15 to 0.63$)$ \\
\hline
\end{tabular}

Note: $\mathrm{Cl}=$ confidence interval, $\mathrm{OR}=$ odds ratio, Ref. = reference.

*Adjusted for substance use disorder and level of prenatal care during pregnancy of first child, year, mother's age, and neighbourhood location and income at birth of first child. 


\section{Limitations}

Our study has several limitations. The R-GINDEX measures only care utilization and not the quality of the prenatal care. Data on several important variables could not be obtained, including women's access to transportation to attend prenatal care visits, smoking status and alcohol use during pregnancy, and Indigenous status. ${ }^{20,36}$ We could not include Indigenous status as a potential confounder in our models; however, most ( $87 \%$ in 2014) children in care are Indigenous. ${ }^{37}$ In Manitoba, Indigenous women are more likely to be involved with child protection services and less likely to access adequate prenatal care..$^{36,37}$ Therefore, the removal of barriers to prenatal care among women whose first child was placed in out-of-home care would likely benefit Indigenous women the most.

Substance use disorder was measured using physician diagnosis; the high specificity but low sensitivity of these diagnoses leads to an underestimation of the true prevalence of substance use disorder in this population. ${ }^{38}$ The omission of these or other unmeasured confounders could introduce bias in the estimates in our adjusted models.

\section{Conclusion}

Manitoba women who had a child placed in out-of-home care were found to have higher rates of inadequate or no prenatal care in subsequent pregnancies than women not having a history of involvement in out-of-home care. Manitoba has one of the highest rates of children in out-of-home care in the world; to ensure generalizability, these findings should be replicated elsewhere. Future research should also focus on the effectiveness of strategies for harm reduction for this group of women to ensure the best outcomes for mother and child.

\section{References}

1. Kogan MD, Martin JA, Alexander GR, et al. The changing pattern of prenatal care utilization in the United States, 1981-1995, using different prenatal care indices. JAMA 1998;279:1623-8.

2. Progress toward target attainment for focus area 16: maternal, infant, and child Health. In: Healthy people 2010: final review. Hyattsville (MD): US Department of Health and Human Services, National Center for Health Statistics; 2012. Available: www.cdc.gov/nchs/data/hpdata2010/hp2010_final_review. pdf (accessed 2018 June 1).

3. Maternal, infant, and child health. In: Healthy people 2020. Washington (DC): US Department of Health and Human Services; 2012. Available: www.healthypeople. gov/2020/topics-objectives/topic/maternal-infant-and-child-health (accessed 2018 June 1).

4. Heaman MI, Sword W, Elliott L, et al. Barriers and facilitators related to use of prenatal care by inner-city women: perceptions of health care providers. BMC Pregnancy Childbirth 2015;15:2.

5. Heaman MI, Green C, Newburn-Cook C, et al. Social inequalities in use of prenatal care in Manitoba. J Obstet Gynaecol Can 2007;29:806-16.

6. Mustard CA, Roos NP. The relationship of prenatal care and pregnancy complications to birthweight in Winnipeg, Canada. Am J Public Health 1994;84:1450-7.

7. Goldenberg RL, Patterson ET, Freese MP. Maternal demographic, situational and psychosocial factors and their relationship to enrollment in prenatal care: a review of the literature. Women Health 1992;19:133-51.

8. Meikle SF, Orleans M, Leff M, et al. Women's reasons for not seeking prenatal care: racial and ethnic factors. Birth 1995;22:81-6.

9. Putnam-Hornstein E, Needell B. Predictors of child protective services contact between birth and age five: an examination of California's 2002 birth cohort. Child Youth Serv Rev 2011;33:1337-44.
10. Wall-Wieler E, Roos LL, Brownell M, et al. Predictors of having a first child taken into care at birth: a population-based retrospective cohort study. Child Abuse Negl 2018;76:1-9.

11. Gilbert R, Fluke J, O'Donnell M, et al. Child maltreatment: variation in trends and policies in six developed countries. Lancet 2012;379:758-72.

12. Debessai $Y$, Costanian C, Roy M, et al. Inadequate prenatal care use among Canadian mothers: findings from the Maternity Experiences Survey. J Perinatol 2016;36:420-6.

13. Annual statistics 2015-2016: seniors and active living. Information management and analytics. Government of Manitoba; 2016. Available: www.gov.mb.ca/ health/annstats/as1516.pdf (accessed 2018 May 28).

14. Singal D, Brownell M, Chateau D, et al. Neonatal and childhood neurodevelopmental, health and educational outcomes of children exposed to antidepressants and maternal depression during pregnancy: protocol for a retrospective population-based cohort study using linked administrative data. BMJ Open 2016;6:e013293.

15. Concept: income quintiles - child health income quintiles. Winnipeg: Manitoba Centre for Health Policy; updated 2018 Apr. 30. Available: http://mchp-appserv. cpe.umanitoba.ca/viewConcept.php?printer=Y\&conceptID=1161 (accessed 2018 May 16).

16. Roos LL, Gupta S, Soodeen R, et al. Data quality in an information-rich environment: Canada as an example. Can J Aging 2005;24(Suppl 1):153-70.

17. Roos LL, Nicol J. A research registry: uses, development, and accuracy. J Clin Epidemiol 1999;52:39-47.

18. Smith M, Lix L, Azimaee M, et al. Assessing the quality of administrative data for research: a framework from the Manitoba Centre for Health Policy. J Am Med Inform Assoc 2017;25:224-9.

19. Alexander GR, Kotelchuck M. Assessing the role and effectiveness of prenatal care: history, challenges, and directions for future research. Public Health Rep 2001;116:306-16.

20. Feijen-de Jong El, Jansen DE, Baarveld F, et al. Determinants of late and/or inadequate use of prenatal healthcare in high-income countries: a systematic review. Eur J Public Health 2012;22:904-13.

21. Term: Child and Family Services Information System (CFSIS). Winnipeg: Manitoba Centre for Health Policy; updated 2012 Oct. 16. Available: http://mchp -appserv.cpe.umanitoba.ca/viewDefinition.php?printer=Y\&definitionID=103818 (accessed 2018 May 16).

22. Funkhouser AW, Butz A, Feng T, et al. Prenatal care and drug use in pregnant women. Drug Alcohol Depend 1993;33:1-9.

23. Concept: substance use disorders / substance abuse - measuring prevalence. Winnipeg: Manitoba Centre for Health Policy; updated 2016 Nov. 22. Available: http://mchp-appserv.cpe.umanitoba.ca/viewConcept.php?conceptID=1471 (accessed 2018 May 16).

24. Heaman MI, Martens PJ, Brownell MD, et al. Inequities in utilization of prenatal care: a population-based study in the Canadian province of Manitoba. BMC Pregnancy Childbirth 2018;18:430.

25. McDonald TP, Coburn A. Predictors of prenatal care utilization. Soc Sci Med 1988;27:167-72.

26. Saadeh FB, Clark M, Rogers M, et al. Pregnant and moving: understanding residential mobility during pregnancy and in the first year of life using a prospective birth cohort. Matern Child Health J 2013;17:330-43.

27. Austin PC. Balance diagnostics for comparing the distribution of baseline covariates between treatment groups in propensity-score matched samples. Stat Med 2009;28:3083-107.

28. Taplin S. Prenatal reporting to child protection: characteristics and service responses in one Australian jurisdiction. Child Abuse Negl 2017;65:68-76.

29. Taplin S, Mattick R. The nature and extent of child protection involvement among heroin using mothers in treatment: high rates of reports, removals at birth and children in care. Drug Alcohol Rev 2015;34:31-7.

30. Roberts SCM, Pies C. Complex calculations: how drug use during pregnancy becomes a barrier to prenatal care. Matern Child Health J 2011;15:333-41.

31. Nathoo T, Poole N, Bryans M, et al. Voices from the community: developing effective community programs to support pregnant and early parenting women who use alcohol and other substances. First Peoples Child Family Rev 2013;8:93-106.

32. Tsantefski M, Humphreys C, Jackson A. Family engagement in the perinatal and infant rights. Child Welfare 2011;90:79-97. 
33. Olds DL, Kitzman H, Knudtson M, et al. Effect of home visiting by nurses on maternal and child mortality results of a 2-decade follow-up of a randomized clinical trial. JAMA Pediatr 2014;168:800-6.

34. Poole N. Evaluation report of the Sheway Project for high-risk pregnant and parenting women. Vancouver: British Columbia Centre of Excellence for Women's Health; 2000. Available: http://bccewh.bc.ca/wpcontent/uploads/2012/05/2000_ Evaluation-Report-of-the-Sheway-Project.pdf (accessed 2018 July 25).

35. Wright TE, Schuetter R, Fombonne E, et al. Implementation and evaluation of a harm-reduction model for clinical care of substance using pregnant women. Harm Reduct J 2012;9:5.
36. Heaman MI, Gupton AL, Moffatt MEK. Prevalence and predictors of inadequate prenatal care: a comparison of Aboriginal and non-Aboriginal women in Manitoba. J Obstet Gynaecol Can 2005;27:237-46.

37. Brownell M, Chartier M, Au W, et al. The educational outcomes of children in care in Manitoba. Winnipeg: University of Manitoba; 2015. Available: http:// mchp-appserv.cpe.umanitoba.ca/reference/CIC_report_web.pdf (accessed 2018 Feb. 18).

38. Kim HM, Smith E, Stano C, et al. Validation of key behaviourally based mental health diagnoses in administrative data: suicide attempt, alcohol abuse, illicit drug abuse and tobacco use. BMC Health Serv Res 2012;12:18.

\section{Competing interests: None declared.}

This article has been peer reviewed.

Affiliations: Department of Pediatrics (WallWieler), Stanford Medicine, Stanford University, Palo Alto, Calif.; Departments of Community Health Sciences (Wall-Wieler, during the conduct of the study; Lee, Roos), and Obstetrics, Gynecology and Reproductive Sciences (Morris); College of Nursing (Thiessen), Rady Faculty of Health Sciences, University of Manitoba, Winnipeg, Man.; Department of Maternal and Child Health (Kenny), The Gillings School of Global Public Health, University of North Carolina at Chapel Hill, Chapel Hill, NC

Contributors: Elizabeth Wall-Wieler conceived the study, and acquired and analyzed the data. Elizabeth Wall-Wieler, Kathleen Kenny, Janelle Lee and Kellie Thiessen drafted the manuscript. Margaret Morris provided important clinical information and Leslie Roos provided critical revision and supervision. All of the authors contributed to the design of the study and the interpretation of the data, revised the manuscript critically for important intellectual content, gave final approval of the version to be published and agreed to be accountable for all aspects of the work.

Funding: Preparation of this manuscript was supported by a Social Sciences and Humanities Research Council of Canada Joseph-Armand Bombardier Canada Doctoral Scholarship.

Data sharing: The data used for this study are owned by the data providers - Manitoba Health, Seniors and Active Living, and Manitoba Families. Access to data is given upon receiving approvals from the University of Manitoba Health Research Ethics Board and the Health Information Privacy Committee, and permissions from both data providers. More information on access to these databases is available at http://umanitoba.ca/faculties/ health_sciences/medicine/units/community health_sciences/departmental_units/mchp/ resources/access.html. The authors do not have any special access privileges that others would not have.

Acknowledgements: Data used in this study are from the Population Research Data Repository housed at the Manitoba Centre for Health Policy, University of Manitoba, and were derived from data provided by Manitoba Health, Seniors and Active Living, and by Manitoba Families under project no. 2016/2017-09. The results and conclusions are those of the authors and no official endorsement by the Manitoba Centre for Health Policy, Manitoba Health, Seniors and Active Living or other data providers is intended or should be inferred.

Accepted: Jan. 22, 2019

Correspondence to: Elizabeth Wall-Wieler, ewallwie@stanford.edu 